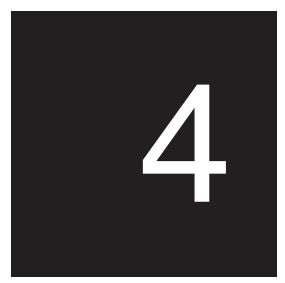

\title{
Gender, culture and sustainable development-the Pacific way
}

\section{Peggy Fairbairn-Dunlop}

Women's work in developing countries has usually been analysed in terms of economic growth models, each of which conclude that women have been adversely affected in the change from traditional to modern economic systems. Liberal-feminist women and development theorists (Boserup 1970; Rogers 1980) identify the decline of women's traditional roles in production, and the importation of Western concepts of women's inferiority as the cause of an erosion of women's status. Increased workloads in subsistence cash cropping, and informal trading, as well as the diminution of women's traditional rights in land, education and decision-making in the national institutions and policymaking bodies are used as evidence to underscore the worsening position of women. Marxist-feminist theorists, on the other hand, see women's low status as resulting from the sexual division of labour which emerges as an expression of women's roles in reproductive activities, and the articulation of these with production outside the home (Beneria and Sen 1981; Nash 1981). They draw attention to women being forced by economic circumstances to work long hours for very low wages, as well as the increasingly common practice of women working a 'double day'.

Pacific women argue that they have not been disadvantaged in the development process, because they have been shielded by customary 
ways. The case studies presented below show tremendous faith of Pacific women in the family system - the family systems that are central to both Pacific women's vision of what development should be (as documented in the Pacific Platform of Action for Sustainable Development) and to the strategies Pacific women are using to achieve their development goals. At the same time, while Pacific women are preserving the customary ways, the question must be raised of whether the customary ways, as they are practised, are ensuring women's physical, social, economic and spiritual well-being in these times of transition. Women's vulnerability in times of rapid change is briefly discussed.

\section{Building on the customary systems}

\section{Case one-the vision of Pacific women}

The Pacific Platform of Action (PPA) for Sustainable Development came into being as a direct result of the region's preparations for the Beijing Women's International Conference in 1995. The PPA represents a major milestone for Pacific women. Until the PPA was published, Pacific women did not have a regional policy document, and there were very few national policy statements or reports about the situation of women. As a result, government and NGO programs lacked an overall cohesion: they were often disjointed, fragmentary, and sometimes more externally than internally driven. The PPA gave Pacific women a mandate. This baseline document-produced by representatives from all Pacific nations-now serves as a guideline for national and regional planning.

Where did the drive to write this regional statement begin? In late 1994 I was asked by ESCAP to prepare a regional report on Pacific progress for forward looking strategies, information from which would be included in an Asia-Pacific Report for Beijing. ${ }^{1}$ In the Decade for Women which followed (1985-95), Nairobi delegates were charged with addressing these goals, and then reporting their progress back to the 1995 Conference at Beijing.

This request from ESCAP for a regional Pacific report raised a number of questions

- were Pacific women aware of, or trying to implement the forward looking strategies (FLS)?

- were the forward looking strategies appropriate for the Pacific? 
- did Pacific women want to be subsumed, yet again, into another Asia-Pacific paper?

All too often, as Pacific delegates attending conferences, we find that our input is 'lost' in Asia concerns, the assumption being that Pacific needs are but a microcosm of those of Asia, or that our 'smallness' (in comparison with Asia) makes our concerns insignificant. This is as partly our fault. We continually call attention to our 'uniqueness', but at the same time we have seldom examined or documented what makes us different, nor have we networked to present a unified Pacific voice on the global scene.

In discussions with the Pacific Women's Bureau of the South Pacific Commission (SPC), it was agreed that the real priority for Pacific women was a regional report which reflected women's present status, their vision for the future and ways to achieve this vision-in short, a sort of a Pacific FLS. Many of these goals and strategies would undoubtedly be similar to the global forward looking strategy, while others might be different. Such a report could be included in the proposed Asia-Pacific paper, but most importantly, it would also serve as a much needed strategy-guiding document for national women's machineries and for the SPC women's regional program.

The initial preparation years of the PPA in 1994-95 became an intensive, sometimes frenzied but always jam-packed learning time as Pacific women from all walks of life learnt about women's experiences globally and then applied these findings to their own situation. The substantial regional and national commitment to this program was backed by a tremendous spirit of good will from regional and national government organisations, NGOs, and donors. For many members of the national teams formed to gather cross sectional data for national reports, this was the first time they had read the forward looking strategy, and/or asked themselves the question, 'what do we want development to bring for ourselves, our children and our community?' Team members asked questions which were not often raised in national forums, and answered these with extreme honesty and fearlessness. They questioned the merits of planning driven wholly by economic concerns; the economic, social and physical vulnerability experienced by low-income families, and households headed by women today; the effects of unemployment and underemployment, illiteracy and increased violence against women and children; the concerns of youth, and the increasing incidence of poverty-related health issues in the Pacific. 
When the national women's reports were completed, these materials were set with other regional data so as to identify the key issues of concern for Pacific women in a draft PPA. This draft was then presented to the Sixth Triennial Conference of Pacific Women, held in Noumea in May 1994, where it was reviewed and rewritten over four days (and nights) by nearly 200 delegates, until a regional document was agreed upon. In these workshop sessions, Pacific women learnt to listen to each other, to look beyond their own immediate concerns, recognise commonalities of experience and to accept different viewpoints. They learnt that ideas should be backed by data, to search for cause and effect relationships, and to lobby for their principles. In short, women learnt to work together to create a regional statement they could support.

The PPA is very much a Pacific document with culture at its centre. The Noumea Declaration - the preamble to the PPA—highlights the centrality of custom, tradition and family to Pacific women's vision of sustainable development, with the family as the basic block on which sustainable development must be built. The Declaration emphasises the uniqueness of the Pacific region

- the central role of custom and tradition

- the primacy of the family

- the strong affinity of our people with the land

- the unique challenges we face as a consequence of our history, demography and geography.

The 13 areas of critical concern identified in the PPA again directly reflect the Pacific social, economic and cultural context-the semisubsistence nature of Pacific economies (as in the role of women in agriculture and fishing); shared decision-making, and the belief that the advancement of women would proceed within the context of environment, culture and the family mechanisms. The 13 areas of critical concern are

- health

- education and training

- economic empowerment

- agriculture and fishing

- legal and human rights

- shared decision-making

- environment

- culture and the family

- mechanisms to promote the advancement of women 
- violence

- peace and justice

- poverty

- indigenous people's rights.

When the Pacific delegates presented the PPA to the Asia Pacific meeting at Jakarta in late 1994, they experienced the joy and power which comes with having the statement of a well-defined vision and presenting this vision as a unified regional voice. At Jakarta, Pacific women finetuned their skills in presenting a case, listening, negotiating and prioritising-with some success. Many of the Pacific concerns were included in the Jakarta Declaration-the Asia Pacific statement for Beijing. Others were not. Even issues that were not included in the Asia Pacific Report were still critical issues for the Pacific and a starting point for Pacific development interventions.

The areas of common concern included in both the Pacific Platform for Action and the Jakarta Declaration included

- the growing feminisation of poverty

- inequality in women's access to, and participation in economic activities

- inadequate recognition of the role and concerns of women in environment and natural resource management

- inequitable access to power and decision-making

- violation of women's human rights

- inadequate, or lack of access to health facilities

- lack of equality and access to education and literacy provision

- inadequate mechanisms for promoting the advancement of women

- inadequate recognition of women's role in peace-building.

The Pacific issues of concern that were not incorporated were

- indigenous women's rights

- insufficient support, recognition and promotion of women's participation in agriculture and fisheries, and in particular, women's roles in food security

- inadequate mechanisms to preserve customs, cultural and traditional values and social safety nets.

The PPA has become a manifesto of Pacific women, for them to use as a guide, to challenge, and to review. This baseline policy document stresses women's firm commitment to family systems and the belief that family systems are the key to sustainable development for Pacific women, their families, communities and nations. 


\section{Case two-the economic strategies of Pacific women}

Family systems are often described in the development literature as being 'hindrances' to economic development. The following two examples show how Pacific women are using their family systems to encourage and enhance economic development options. Aggie Grey's enterprise is an example of a business which has used family systems to grow 'vertically' in size, to increase the numbers employed and capital outlay. The second example of women entrepreneurs shows women who prefer to run a number of small businesses at one time, following a 'lateral' pattern of business development, rather than increasing the size of a single business.

Building a large enterprise-Aggie Grey's, Samoa. Aggie's holds pride of place as the most well-known hotel in the South Pacific. For tourists it is a Pacific landmark, while to economic experts it is proof that an indigenous business enterprise can 'work'. Aggie reportedly went into business following the bankruptcy of her husband's business during the depression years of the 1930s, because she was determined that her younger children would enjoy the same education as her elder children. Aggie began by selling baskets of fruit and vegetables to the wives of New Zealand administrators. From this beginning, Aggie progressed to handicrafts sales, and then to hospitality. The modest two-roomed guesthouse Aggie opened in the 1930s has now grown into an internationally recognised multi-million dollar hotel, incorporating 154 rooms, a gift shop, tours and an extensive farm to supply fresh produce to the hotel kitchens. Each new 'development' represents a response to changing social conditions, such as the stationing of thousands of US military in Samoa in the 1940s; the growth of air travel—-the introduction of three-day package TEAL flights, Pan-Am flights from Hawaii to American Samoa and the development of Polynesian Airlines as the national carrier-and the shooting of a major movie, Return to Paradise, in Samoa, featuring international box-office stars Gary Cooper and Roberta Haines.

A statement frequently heard is that 'Aggie's is run like a chiefly system with Aggie at the head'. The relationship between the Grey family and their staff is personal rather than directive: every worker feels they have a personal stake in the business. Alailima writes

Aggie looked at her staff not as employees but as members of her own extended families. Many of them were really her kin...Though Aggie held no title, they thought of her as the chief of this large household. She assigned jobs, gave instruction, inspected progress and scolded 
malingerers. She made very clear what she expected and was by no means easy to please. In return Aggie...provided more than wages. She acted like a parent, designing their clothes, sticking flowers over their ears, and dabbing her 'daughters' with perfume. She advised them about sex. When they were sick she nursed them, when they were in trouble she stuck by them and when they had a faalavelave [a special demand] she was generous (1988:294).

Aggie's business dealings are based on family, personal friendships and trust. For example, she always purchased handicrafts and other hotel supplies from certain villages and buyers, thus guaranteeing these producers a market. In many cases she gave higher prices than a piece of handicraft warranted, and/or created work for those urgently in need of cash. As in a family, staff members are adept at most of the jobs needed to keep the hotel running smoothly. The girls who clean rooms by day are the dancers at the floorshow in the evening, while the pool attendants and gardeners provide the musical back-up support for the fiafia, or party. It is the tradition also for a member of the Grey family to perform the taualuga (last dance-the most important) at the weekly fiafias. In the early days Aggie was the taualuga. Now her grand-daughter has this honour. The Grey family, as fitting its prominent chiefly status, give generously to national and local fund-raising efforts-particularly of the Apia village. These gifts reinforce the relationships between the enterprise and the people; as in traditional times true wealth is displayed in giving.

Aggie's continues to draw on family networks to build the business, and by doing so, is not only spreading the benefits of development more evenly, but strengthening family networks. Today Aggie's employs over 250 staff. A daughter-in-law commented that 'We could run the hotel with fewer...but you don't fire family.'

Economic security through a number of small family-based microenterprises, Fiji. The uncertain economic situation in many Pacific countries has seen the increase of informal trade and small businesses, the majority of which are run by women. Many of these largely agriculturally based businesses have become the main source of family income for a growing number of families (see Appendix 1). The WOSED (Women's Social and Economic Development Program) micro-credit program is run by the Division of Women's Affairs, Fiji. It is based on the Grameen model of peer group support and the premise that credit and/or savings is the catalyst that will enable women to develop resources to effect change and thereby contribute to the fulfilment of their personal and family development. WOSED is designed to assist 
unemployed and underemployed women, who are usually unable to meet the collateral and equity required by the formal lending system to gain access to credit. One of the aims of WOSED is that women will learn skills and develop sufficient collateral to access a larger loan from a commercial bank, as they increase the size of their businesses.

A review of WOSED carried out in April 1997 showed that over 250 small loans of under $\mathrm{F} \$ 1000$ had been given out, and some women had taken a second loan. As seen in Table 1, a high percentage of the enterprises undertaken by the women borrowers were agriculturally based, and almost a third were weaving and handicraft production 'for our family living in town', 'for traditional use' and for sale. There were very few non-agricultural enterprises and two enterprises could be classified as 'services' (such as brush cutter and catering hire). All told, the enterprises were family based and physically located within the ambit of both family and community.

Interviews with the women borrowers revealed two further trends: a significant number of WOSED members were engaged in more than one income-earning venture, and, often when one enterprise was operating effectively, women gave this to the care of another family member and then started another small enterprise. For example, the multiple enterprises of a Savusavu solo mother of 8 included vegetable gardening, poultry (father now does this), a piggery (son

\section{Table 4.1 Micro-enterprises by type}

\begin{tabular}{|c|c|}
\hline \\
\hline & $\begin{array}{c}\text { Weaving, } \\
\text { handicrafts }\end{array}$ \\
\hline & Fishing (14) \\
\hline & Poultry (13) \\
\hline & Vegetables (11 \\
\hline & Farming (8) \\
\hline & Pigs (5) \\
\hline & Ducks (6) \\
\hline & Copra (3) \\
\hline & Rice (2) \\
\hline & Bees (1) \\
\hline
\end{tabular}

\section{Sales \\ (98)}

Canteen (43)

Market vendor (35)

Kava (8)

Baking, cakes (3)

Retail shop (2)

Wool (1)

Second-hand

clothing (1)

Snacks,

sweets, peanuts (5)

\section{Clothing \\ related}

(39)

Sewing (19)

Fabric printing,

tie dyeing (12)

Embroidery (8)

\section{Service}

(2)

Brush-cutter (1)

Catering

equipment hire (1)

Source: Fairbairn-Dunlop P. and Struthers J., 1997. Review of the Women's Social and Economic Development Program (WOSED), Ministry of Foreign Affairs and Trade, Wellington. 
helps), and fishing. In addition to this, she and other family members sell produce at the market, at a roadside stall (built on the main road in front of their house) and at a siding on the main bus route to Labasa. This lateral development pattern which sees other family members absorbed into the businesses is seen in Table 4.2.

This lateral pattern of business development no doubt reflects factors such as the desire to spread risks, keep options open, an unwillingness to be burdened by a big debt, and a preference for keeping enterprises at a 'hands on' stage. This pattern is at odds with assumptions that people want to 'grow' a business in size, that larger businesses are 'better' or 'more successful' than smaller business and that people should progress from micro to larger-size loans.

These groups are practising an alternative development paradigm which is a viable strategy in today's rapidly changing social and economic conditions. It is a strategy which has implications for national development planning and service provision as well.

\section{To conclude: are the family systems supporting women?}

These cases have shown that women are choosing development options which build on the strengths of family systems, and therefore preserve the customary ways. Are the customary ways preserving the physical, social, economic and spiritual well-being of women, in these rapidly changing times?

\section{Table 4.2 Pattern of multiple small enterprises and employment for family members}

\begin{tabular}{llllll}
\hline Case & District & Loan 1 & Who helps? & Loan 2 & Who helps? \\
1 & Central & Catering & Daughter & Brush cutter & Son $^{\text {a }}$ \\
2 & Central & Market vendor & Daughter & Canteen & Daughter \\
3 & North & Market vendor & Husband & Food parcels & Husband \\
4 & North & Poultry/pigs & Father & Vegetables & Daughter \\
5 & West & Fishing & Sister & Canteen & Daughter \\
6 & West & Crockery hire & Family & Video filming & Family \\
7 & East & Bread baking & Husband & n.a. & n.a. \\
8 & East & Mat weaving & Daughter $^{\mathrm{a}}$ & n.a. & n.a.
\end{tabular}

n.a. not applicable

a presently unemployed

${ }^{\mathrm{b}}$ child in school at present/ looking to next year.

Source: Fairbairn-Dunlop P. and Struthers J., 1997. Review of the Women's Social and Economic Development Program (WOSED), Ministry of Foreign Affairs and Trade, Wellington. 
Major economic and social transformations are occurring today, and are changing household formations and patterns of obligation rapidly and substantially. New data are showing areas where Pacific women do not enjoy equal chances with males, such as education. Educational equity is particularly critical because education is the key to every other aspect of personal and national development. It is linked with good health, widened employment options, and the sustainable use of natural resources. Education is also positively correlated with population growth, in that women with a higher level of education have fewer children. (Population growth is a critical development issue because Pacific countries have amongst the highest rates of population growth in the world. It is estimated that the region's population will double in 20 years. That over 50 per cent of our populations are aged 15 years and under presents a major challenge to every sustainable development strategy). The general pattern of educational participation and use in the region shows three trends. First, the higher the level of schooling the lower the female participation. For some countries, the major priority is getting and keeping girls in primary schools. In others, women's access to schooling equals males through to secondary schooling, and then there is a large drop out of females at that point. Second, women are grossly underrepresented in the sciences. Third, women's educational achievements do not translate into equal participation in the economic, social or political spheres. The lack of participation of women in national decision-making means that the concerns women see as important, and the alternative strategies women's groups such as WOSED are trying, may not be discussed at these national planning forums.

What are the factors contributing to the present under-use of women's potential? It is probably true that the institutional structures are in place for women to have equal educational access to males, since education is compulsory in most Pacific countries. However, are there social attitudes and circumstances at play which work to prevent women from fully using these chances-are girls kept home from school to help in the home? Is it seen as a waste of time for girls to enrol in tertiary study, and, is science 'too hard' for girls? Or, is the belief still widely held that women do not need as much education as males because their brothers or their families will look after them?

Despite our protests to the contrary, family systems are not protecting Pacific women as in past. The disastrous effects of the weakening of family systems in these transition times is seen in the 
increased number of marriage breakdowns, households headed by women; land disputes and misuse of family land (as in logging contracts), unemployment and incipient poverty (overcrowded living conditions, poor nutrition), increased crime, increases in the reported incidence of violence against women and children, and the lack of care for the elderly, once the honoured members of society. The growth of households headed by women is clear in all our countries, and many of these families are living in conditions below the poverty line, as shown in Appendix 2.

Societies develop their own patterns of organisation to ensure that the social, economic physical and spiritual needs of their members are met. The communal systems-including the large subsistence sector, strong cultural identity and traditional values and the stable social fabric based on the village community and extended family systemshave prevented the onset of severe poverty on a large scale in every Pacific country. Sustainable progress in human development will depend on strengthening these systems to ensure that social, economic and structural changes will continue to improve people's lives and their well-being. It is time to review the customary systems and the gender roles these promote to see whether they are working in the interests of women and their families. 


\section{Appendix 1}

The following data from the Solomon Islands and Vanuatu give some idea of the extent of women's activities in the informal sector and their importance to family security.

Solomon Islands, 1993. (Sample size: 323 randomly selected women.) Vanuatu, 1994. (Sample size: 949 women market vendors from Efate, Santo, Malekula and Ambae).

Two-thirds of a sample were self-employed at the time of the interviews. Of this two thirds, 75 per cent said they spent 16 hours or more each week on their income-generating ventures.

- More than one third of these women were sole income providers.

- Agriculture was the major enterprise-farm gardening (38 per cent), food catering (21 per cent), crafts (15 per cent) and textiles (11 per cent).

- 40 per cent sold their products directly to consumers at the market, 34 per cent sold from their homes, and 16 per cent from shops.

- Over 75 per cent had not received any assistance to run their businesses, whether from relatives, banks or other sources.

- 75 per cent were married (average 5 children) and 25 per cent lived in households of more than seven people. More than 50 per cent had only a few years of primary school education and almost one-fifth had no formal education at all. 25 per cent were not able to write in any language and almost one-third could not do any calculations.

Source: Ward, M. and Arias, F., 1995. Employment for Women in Solomon Islands, National Centre for Development Studies, The Australian National University and ILO/UNDP, Canberra.

The survey found

- profits from these sales was the household's major source of income for 64 per cent of the sample- 89 per cent of these profits was spent on household expenses including food, 37 per cent on school fees

- agricultural goods were the major items sold. However, women did not specialise in any one item but engaged in multiple economic activities (MEA) thus spreading their risks over a number of options, and working at any activity 
which would 'ensure our children have food on the table'

- the main source of loans to develop their business for 73 per cent, was from family members; 18 per cent obtained them from an unstated source, 12 per cent from commercial banks and credit unions; and 4 per cent borrowed from the Development Bank

- 28 per cent has attended a training course.

Source: Women's Business Unit of the Department of Cooperatives and Rural Business Development, and Statistics Department, Vanuatu.

\section{Appendix 2}

\section{Some Pacific realities}

- 50 children die each day

- 10,000 children do not reach their fifth birthday

- 1,100 women die from birth-related problems each year

- 1.4 million adults cannot read nor write-the majority of these are women

- 40 per cent of children have less than 8 years of schooling

- there are growing inequalities, poverty and human distress

- the region's rainforests will be gone in less than 20 years

- massive depletion of reef, lagoon and ocean resources is taking place

- the population of the region will double in 20 years, urban populations will reach 43 per cent

- an extra 3 million wage-earning jobs will be needed in the next 20 years.

\section{Note}

1 The Forward Looking Strategies derived from the 1985 Women's International Conference in Nairobi, which passed two major resolutions, CEDAW (Convention for the Elimination of Discrimination against Women) and the FLS. 


\section{References}

Alailima, F., 1988. Aggie Grey: a Samoan saga, Mutual Publishing Company, Honolulu.

Beneria, L. and Sen, G., 1981. 'Accumulation, reproduction and women's roles in economic development: Boserup revisited', Signs 7(2):279-300.

Boserup, E., 1970. Women's Roles in Economic Development, George Allen and Unwin, London.

Fairbairn-Dunlop P., 1994. 'Gender, culture and tourism development in Western Samoa', in J. Momsen and Y. Kinnaird (eds), Gender: the tourism dimension, Boulder Press, Westview.

— 1995. The road to Beijing: the path from Apia, Paper presented to the Seminar on Gender and Development Issues at the Asian Development Bank's 28th Annual Meeting of Governors in Auckland, New Zealand.

Fairbairn-Dunlop, P. and Struthers, J., 1997. Review of the Women's Social and Economic Development Program (WOSED), Ministry of Foreign Affairs and Trade, Wellington.

Nash J., 1981. 'Ethnographic aspects of the world capitalist system', Annual Review of Anthropology, 10:94-119.

Rogers, B., 1980. The Domestication of Women, Tavistock, London.

South Pacific Commission, 1995. Pacific Platform of Action: rethinking sustainable development for Pacific women towards the year 2000, South Pacific Commission, Noumea.

UNDP, 1994. The Pacific Human Development Report, UNDP, Suva.

Ward, M. and Arias, F., 1995. Employment for Women in Solomon Islands, National Centre for Development Studies, The Australian National University and ILO/UNDP, Canberra. 